\section{Exposure of patients to ionising radiation during lung cancer diagnostic work-up ABSTRACT}

We examined the dose of radiation received during diagnosis of lung cancer as this may add to the risk of a second primary cancer. Patients undergoing surgery $(n=40)$ or (chemo)radiotherapy $(\mathrm{n}=40)$ received comparable doses $(28.6$ and $25.8 \mathrm{mSv}$, respectively), significantly higher than that for supportive care $(\mathrm{n}=40 ; 15.1 \mathrm{mSv})$. The effective dose of radiation received was higher for early stage disease than for those with metastatic disease. The mean lifetime attributable risk of malignancy for those receiving treatment with curative intent in our cohort was $0.059 \%$, and lung-specific risk $0.019 \%$

\section{INTRODUCTION}

During work-up of patients with (suspected) lung cancer for treatment with curative intent, healthy tissues are exposed to ionising radiation. This may add to the risk of a future second primary cancer and is particularly pertinent to the growing number of younger long-term survivors. At present, the total radiation dose received by patients during diagnostic work-up is not monitored or restricted, and there remains a paucity of literature on the subject.

Given recent changes in investigation algorithms used in lung cancer ${ }^{1}$ and the importance of understanding the risks associated with ionising radiation, we sought to evaluate diagnostic radiation exposure in a cohort of patients investigated through the Papworth and Addenbrooke's Thoracic Oncology Service.

\section{METHODS}

The cumulative radiation dose received by patients undergoing investigation for treatment with curative intent for primary lung cancer at Papworth and Addenbrooke's Hospitals between December 2012 and March 2014 was calculated. Retrospective data were gathered from electronic reporting systems including patient demographics, stage and type of cancer, and participation in clinical studies involving ionising radiation (see online supplementary tables S1-S4). Information on all radiological investigations involving ionising radiation between the first targeted investigation and the start of definitive treatment was gathered. Similar data for a group of patients $\quad(n=40) \quad$ undergoing best supportive care (BSC) were also collected. If data on individual studies were not available, an estimate derived from local diagnostic reference levels was used. The total effective radiation dose was calculated for each patient, and percentage lifetime attributable risk (LAR) estimated using conversion coefficients in HPACRCE-028 and HPA-CRCE-012, NRPB-W 67 and ICRP106. ${ }^{2-5}$

Comparisons between groups were made using Student's t-test, with a value of $\mathrm{p}<0.05$ considered significant.

\section{RESULTS}

The mean cumulative dose of radiation received by 80 patients undergoing investigation for treatment with curative intent (surgery or radical (chemo)radiotherapy) was $27.6 \mathrm{mSv} \pm 0.9$ (table 1). Patients in the surgical and (chemo)radiotherapy groups received comparable dosessurgery $28.6 \mathrm{mSv}$, (chemo)radiotherapy $25.8 \mathrm{mSv} ; \mathrm{p}=0.89$ (table 1 and figure 1). This was significantly higher than those who received BSC $(n=40 ; 15.1 \mathrm{mSv} \pm 1.4$; $p<0.05)$. When stratified by the stage of disease (figure 2), the effective dose of radiation received was higher for early stage disease than for those with metastatic disease $(\mu=26.9 \mathrm{mSv}$ for stage I, $24.6 \mathrm{mSv}$ for stage II, $22.3 \mathrm{mSv}$ for stage III and $14.4 \mathrm{mSv}$ for stage IV). As might be expected, there was a correlation between body mass and effective dose (see online supplementary figure $1 ; \mathrm{r}=0.44$, $\mathrm{p}<0.05$ ), but no significant correlation with patient age (see online supplementary figure $2 ; r=0.058, p=0.52)$. For patients undergoing treatment with curative intent, the median number (range) of investigations undertaken was CT staging $1(0-4)$; CT head $1(0-2)$; CT-guided biopsy $1(0-3)$ and positron emission tomography (PET)-CT 1 (0-2) (see online supplementary table S5).

The mean LAR of malignancy for those receiving treatment with curative intent was $0.059 \%$, that is, 5.9 in 10000 longterm survivors would be expected to develop a second primary cancer as a direct consequence of diagnostic imaging investigations. The lung-specific risk was $0.019 \%$ (table 2).

\section{DISCUSSION}

Despite lung cancer being one of the most common cancers globally, there is a paucity of information on the usual radiation dose patients receive during diagnostic work-up. We have shown that the mean cumulative dose of radiation received by patients undergoing investigation for treatment with curative intent (surgery, radical (chemo)radiotherapy) is around $28 \mathrm{mSv}$ substantially lower than that identified by Stiles et $a l^{6}$ who found that in 94 patients, the 3 -year median estimated dose was $84.0 \mathrm{mSv}$ and that the highest dose occurred in the preoperative year. In any one year, $66 \%$ of their patients received more than $50 \mathrm{mSV}$, while $19 \%$ received over $100 \mathrm{mSv}$. Only one of our 80 patients exceeded $50 \mathrm{mSv}$. Our finding that the radiation dose received by those who ultimately received treatment with curative intent was significantly higher than the dose received for those treated with BSC is not unexpected. This is because those being assessed for treatment with curative intent underwent additional investigations including PET-CT and CT head, and some patients being assessed for surgical resection required coronary angiography and/or quantitative ventilation/perfusion scintigraphy. The overall reduction in radiation dose compared with the work by Stiles et $a l^{6}$ is most likely due to improvements in radiation technology over the last decade, which allows equivalent imaging at lower radiation doses.

Although we have estimated the associated LAR of malignancy, this value remains difficult to interpret with regard to setting 'limits' of acceptability. Typically, LAR values are calculated in healthy subjects, but the effect of radiation exposure in a high-risk tobacco-exposed population may be greater. A number of factors should be considered. Age at presentation may be significant. For patients presenting over age 70 , the risk of developing a second primary cancer as a result of previous radiation exposure is likely to be considerably lower than the risk conferred by previous/current cigarette smoking. However, for younger patients being treated with curative intent,

Table 1 Effective dose of radiation received $/ \mathrm{mSv}$

\begin{tabular}{lllll}
\hline Treatment group & $\mathbf{N}$ & Mean/ $\boldsymbol{\mu}(95 \% \mathrm{Cl})$ & $\mathbf{S E M}$ & $\mathbf{S D} / \boldsymbol{\sigma}$ \\
\hline Surgical & 40 & $28.6(26.0$ to 31.2$)$ & 1.33 & 8.42 \\
(Chemo)radiotherapy & 40 & $25.8(23.5$ to 28.1$)$ & 1.19 & 7.50 \\
Total curative intent & 80 & $27.6(25.8$ to 29.4$)$ & 0.90 & 8.01 \\
Best supportive care & 40 & $15.1(12.4$ to 17.8$)$ & 1.36 & 8.60 \\
\hline
\end{tabular}




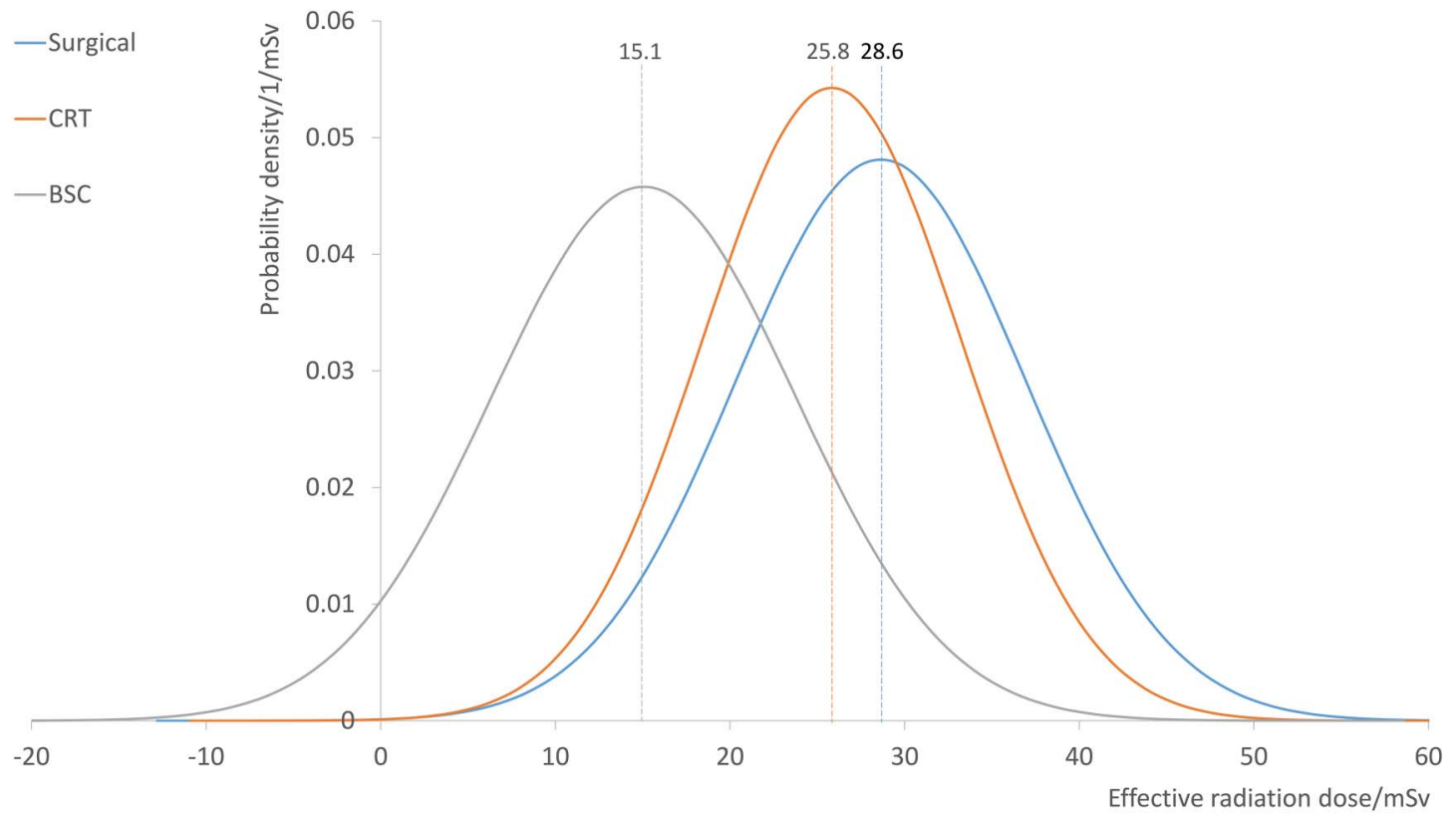

Figure 1 Effective radiation dose (mSv) received by patients during diagnostic work-up stratified by surgical, (chemo)radiotherapy (CRT) and best supportive care (BSC) groups.

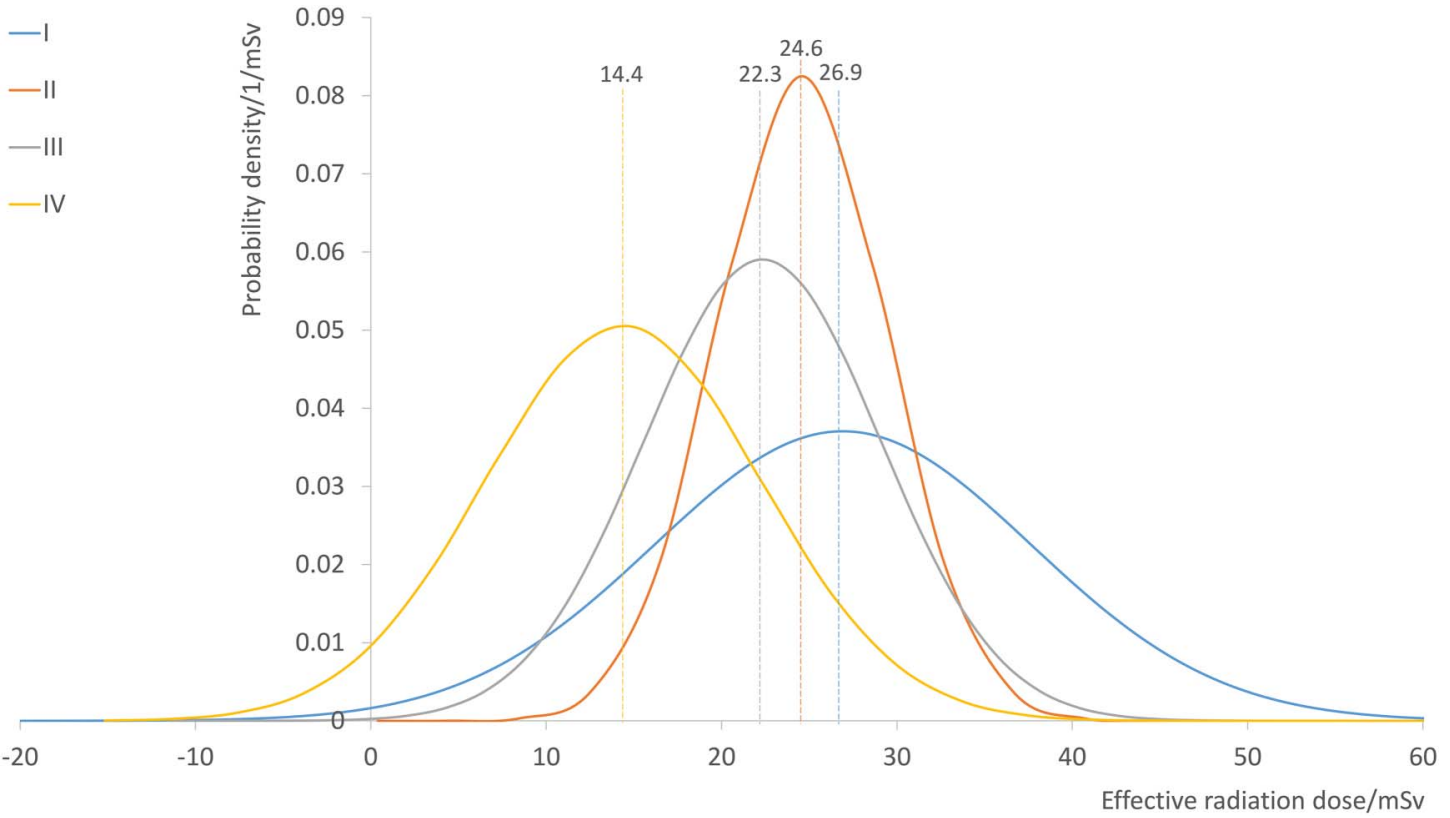

Figure 2 Effective radiation dose (mSv) received by patients during diagnostic work-up stratified by stage of disease.

Table 2 Lifetime added risk of malignancy/\%

\begin{tabular}{|c|c|c|c|c|c|c|c|}
\hline \multirow[b]{2}{*}{ Treatment group } & \multirow[b]{2}{*}{$\mathrm{N}$} & \multicolumn{3}{|l|}{ Total } & \multicolumn{3}{|l|}{ Lung } \\
\hline & & Mean/ $\mu$ & SEM & $\mathrm{SD} / \sigma$ & Mean $/ \mu$ & SEM & $\mathrm{SD} / \sigma$ \\
\hline Surgical & 40 & 0.062 & 0.00013 & 0.00082 & 0.019 & 0.00011 & 0.00072 \\
\hline (Chemo)radiotherapy & 40 & 0.056 & 0.00015 & 0.00097 & 0.019 & 0.00026 & 0.00017 \\
\hline Total curative intent & 80 & 0.059 & 0.00014 & 0.00090 & 0.019 & 0.000019 & 0.00012 \\
\hline
\end{tabular}

thought should be given to LAR given that they will likely have longer life expectancy.

In conclusion, newer algorithms for investigating patients with suspected lung cancer, combined with improvements in imaging technology, have reduced the average radiation dose in patients receiving definitive treatment to $28 \mathrm{mSv}$. Although this is considerably lower than previous reports, it is still associated with a quantifiable mean LAR of malignancy of $0.059 \%$ in our patient cohort.

Robert C Rintoul, ${ }^{1}$ Rachel Atherton, ${ }^{2}$ Katharine Tweed, ${ }^{3}$ Stuart Yates, ${ }^{4}$ Edwin R Chilvers ${ }^{5}$

$R C R$ and RA are joint first author of this letter.

'Department of Thoracic Oncology, Papworth Hospital, Cambridge, UK

${ }^{2}$ University of Cambridge School of Clinical Medicine, Cambridge, UK

${ }^{3}$ Department of Radiology, Papworth Hospital, Cambridge, UK 
${ }^{4}$ East Anglian Regional Radiation Protection Service, Addenbrooke's Hospital, Cambridge, UK

${ }^{5}$ Department of Medicine, University of Cambridge School of Clinical Medicine, Addenbrooke's Hospital, Cambridge, UK

Correspondence to Dr Robert C Rintoul, Department of Thoracic Oncology, Papworth Hospital NHS Foundation Trust, Cambridge CB23 3RE, UK; Robert. rintoul@nhs.net

Contributors The original project was conceived by ERC. All authors developed the methodology. RA and $K T$ collected data which were analysed by RA, RCR and ERC. RCR produced the first draft of the manuscript which was reviewed and approved by all.

Funding RCR is part-funded by the Cambridge Biomedical Research Centre and Cancer Research UK Cambridge Centre.

Competing interests None declared.

Provenance and peer review Not commissioned; externally peer reviewed.

- Additional material is published online only. To view please visit the journal online (http://dx.doi.org/10. 1136/thoraxjnl-2016-209641).
2 Wall BF, Haylock R, Jansen JTM, et al. Radiation risks from medical $X$-ray examinations as a function of the age and sex of the patient. HPA-CRCE-028. Chilton: HPA Centre for Radiation, Chemical and Environmental Hazards, 2011.

To cite Rintoul RC, Atherton R, Tweed K, et al. Thorax 2017;72:853-855.

Received 28 October 2016

Revised 5 March 2017

Accepted 28 March 2017

Published Online First 25 April 2017

\section{S Linked}

http://dx.doi.org/10.1136/thoraxjnl-2017-210360

Thorax 2017;72:853-855.

doi:10.1136/thoraxjnl-2016-209641

\section{REFERENCES}

1 National Institute for Health and Clinical Excellence. Lung Cancer diagnosis and management. NICE guidelines (CG121), 2011.
3 Hart D, Wall BF, Hillier MC, et al. Frequency and collective dose for medical and dental $X$-ray examinations in the UK. HPA-CRCE-012. Chilton: HPA Centre for Radiation, Chemical and Environmental Hazards, 2008.

4 Shrimpton PC, Hillier MC, Lewis MA, et al. Doses from computed tomography (CT) examinations in the UK: 2003 review. NRPB-W67. Chilton: National Radiation Protection Board, 2005.

5 Mattsson S, Johansson L, Liniecki J, et al. Radiation dose to patients from radiopharmaceuticals addendum 3 to ICRP publication 53. ICRP Publication 106. Ann ICRP 2008;38:1-197.

6 Stiles BM, Mirza F, Towe CW, et al. Cumulative radiation dose from medical imaging procedures in patients undergoing resection for lung cancer. Ann Thorac Surg 2011;92:1170-9. 